\title{
Protein Matrices for Improved Wound Healing: Elastase Inhibition by a Synthetic Peptide Model
}

\author{
Andreia Vasconcelos, ${ }^{,}{ }^{\dagger}$ Ana Paula Pêgo, ${ }^{\ddagger}$ Lara Henriques, ${ }^{\ddagger}$ Meriem Lamghari, ${ }^{\ddagger}$ and \\ Artur Cavaco-Paulo*,† \\ Universidade do Minho, Departamento de Engenharia Têxtil, Campus de Azurém, \\ 4800-058 Guimarães, Portugal, and INEB - Instituto de Engenharia Biomédica, Divisão de Biomateriais, \\ Universidade do Porto, Rua do Campo Alegre 823, 4150-180, Porto, Portugal
}

Received January 26, 2010; Revised Manuscript Received July 16, 2010

\begin{abstract}
The unique properties of silk fibroin were combined with keratin to develop new wound-dressing materials. Silk fibroin/keratin (SF/K) films were prepared to reduce high levels of elastase found on chronic wounds. This improved biological function was achieved by the incorporation of a small peptide synthesized based on the reactive-site loop of the Bowman-Birk Inhibitor (BBI) protein. In vitro degradation and release were evaluated using porcine pancreatic elastase (PPE) solution as a model of wound exudate. It was found that biological degradation and release rate are highly dependent on film composition. Furthermore, the level of PPE activity can be tuned by changing the film composition, thus showing an innovative way of controlling the elastase-antielastase imbalance found on chronic wounds.
\end{abstract}

\section{Introduction}

Wound healing is a specific biological process related to the general phenomenon of growth and tissue regeneration. Wound healing progresses through a series of interdependent and overlapping stages in which a variety of cellular and matrix components act together to reestablish the integrity of damaged tissue and the replacement of lost tissue. ${ }^{1-3}$ The interruption of the orderly sequence of events during the healing process results in chronic wounds. ${ }^{4,5}$

Skin ulcers are the most common types of chronic wounds and are the focus of this study. These wounds can be created by many factors including vascular insufficiency, prolonged inflammation, pressure necrosis, physical agents, infection, and cancer. ${ }^{6}$ Chronic wounds stop the healing process in the inflammatory phase, remaining nonhealed for several months or even years.

Excessive amounts of exudates are present in these types of wounds. Although wound exudate is a key component in all stages of the wound healing, irrigating the wound continuously and keeping it moist, ${ }^{1,7}$ the excessive production of exudates can cause maceration of healthy skin tissue around the wound, inhibiting the healing. In addition, exudate from chronic wounds differs from acute wounds fluid, containing higher levels of tissue destructive protease enzymes, namely, matrix metalloproteinases (MMPs) and polymorphonuclear (PMN) elastase. ${ }^{8-12}$ The excessive action of elastase leads to reduce amounts of growth factors ${ }^{13}$ and endogenous proteinase inhibitors, causing the cleavage of collagen, elastin, and fibronectin and consequently the destruction of extracellular matrix. ${ }^{10}$ As a result, there has been considerable interest in the design of inhibitors that restore the elastase-antielastase imbalance.

Bowman-Birk inhibitors (BBIs) are small plant proteins of typically 60 to 90 residues stabilized by seven disulfide bridges. They have a symmetrical structure of two tricyclic domains,

\footnotetext{
* Corresponding authors. artur@det.uminho.pt (A.C.-P.); andreiav@ det.uminho.pt (A.V.).

$\dagger$ Universidade do Minho.

Universidade do Porto.
}

each containing an independent binding loop. ${ }^{14-17}$ The inhibition of serine proteinases is often mediated by these binding regions. The reactive site loop is fixed in a "canonical" conformation that is complementary to the proteinase active site. ${ }^{18,19}$ Small peptides mimicking the reactive-site loop of BBI protein have shown to retain much of the inhibitory activity of the complete protein. ${ }^{20}$

This study focus on the development of wound dressings with the ability to control elastase activity. Silk fibroin and keratin blends were used to incorporate a synthetic BBI peptide. The peptide sequence was removed from a combinatorial library of synthetic BBI-based peptides. ${ }^{21}$ The excellent properties of silk fibroin such as high mechanical strength, low degradability, and biocompatibility were combined with keratin protein to modulate the physical and bifunctional properties of the final material to fulfill the wound healing needs.

\section{Materials and Methods}

2.1. Materials. The porcine pancreatic elastase (PPE) was purchase from Sigma, Spain. The peptide 5(6)-carboxyfluoresceinYCQPPWSATCF-OH was synthesized by JPT Peptide Technologies GmbH (Germany). The NIH 3T3 cell line (mouse embryonic fibroblasts) was purchased from the European Collection of Cell Cultures (ECACC). All other reagents were analytical grade and purchased from Sigma, Spain.

2.2. Preparation of Aqueous Silk Fibroin and Keratin Solutions. Silk cocoons from B. mori were donated from "Sezione Specializzata per la Bachicoltura" (Padova). Silk fibroin (SF) was purified from its sericin content, as previously described. ${ }^{22}$ The cocoons were cut, cleaned from debris and larvae, and autoclaved for $30 \mathrm{~min}$ at $120{ }^{\circ} \mathrm{C}$. SF was then thoroughly washed with distilled water and dried overnight at room temperature.

We prepared SF solution $1 \%(\mathrm{w} / \mathrm{v})$ by dissolving $1 \mathrm{~g}$ of degummed silk fibers into $10 \mathrm{~mL}$ of saturated aqueous $\mathrm{LiBr}$ at $60^{\circ} \mathrm{C}$ for $3 \mathrm{~h}$. The solution was then diluted by the addition of $90 \mathrm{~mL}$ of deionized water.

We prepared keratin $(\mathrm{K})$ solution $1 \%(\mathrm{w} / \mathrm{v})$ by immersing $1 \mathrm{~g}$ of delipided wool fabric, provided by Albano Antunes Morgado Lda (Portugal), in $10 \mathrm{~mL}$ of a solution containing $8 \mathrm{M}$ urea, 0.2 M SDS, 
and $0.5 \mathrm{M} \mathrm{Na}_{2} \mathrm{~S}_{2} \mathrm{O}_{5}$. The mixture was heated to $60{ }^{\circ} \mathrm{C}$ for $12 \mathrm{~h}$. Both solutions were filtered and dialyzed against distilled water using cellulose tubing (molecular-weight cutoff of 12 00-14 $000 \mathrm{Da}$ ) until complete removal of salts was achieved.

2.3. Preparation of Blended Silk Fibroin/Keratin Films. Keratin (K) and SF solutions (10 mL of final volume) were blended in the ratios of $80 / 20,60 / 40$, and $40 / 60$ of $S F / K$. The blends were cast in plastic Petri dishes with a circular area of $40 \mathrm{~cm}^{2}$ and dried at room temperature. The controls are $100 \% \mathrm{SF}$ and $100 \% \mathrm{~K}$. The resulting films were $0.03 \mathrm{~mm}$ in average thickness.

To induce the transition of SF from random coil to $\beta$-sheet structure and consequently insolubility, all films were immersed in $90 \%$ (v/v) methanol solution for $30 \mathrm{~min}$ and then washed in distilled water and air-dried. All films used were submitted to this treatment.

2.4. In Vitro Degradation. $S F / K$ films were incubated, for 14 days, at $37{ }^{\circ} \mathrm{C}$ in a solution containing $0.1 \mathrm{U} / \mathrm{mL}$ of PPE in $100 \mathrm{mM}$ Tris$\mathrm{HCl}$ buffer, $\mathrm{pH}$ 8.0. The control samples were incubated in the same buffer without PPE and submitted to the same conditions.

Solutions were changed every $12 \mathrm{~h}$. At designated time points, samples were washed thoroughly with distilled water, dried in a desiccator, and weighed to estimate the extent of degradation by the following equation

$$
\text { weight loss }(\%)=\frac{m_{0}-m_{\mathrm{f}}}{m_{0}} \times 100
$$

where $m_{0}$ is the initial dry mass of the sample and $m_{\mathrm{f}}$ is the final dry mass.

2.5. Swelling Ratio of SF/K Films. Dry SF/K films $\left(60^{\circ} \mathrm{C}\right.$ for $\left.24 \mathrm{~h}\right)$ were immersed in $100 \mathrm{mM}$ Tris- $\mathrm{HCl}$ buffer, $\mathrm{pH} 8.0$ at $37^{\circ} \mathrm{C}$ for $24 \mathrm{~h}$. The excess of buffer was removed, and the wet weight of the film was determined. The swelling ratio of the film was calculated as follows

$$
\text { swelling ratio }=\frac{W_{\mathrm{S}}-W_{\mathrm{d}}}{W_{\mathrm{d}}}
$$

where $W_{\mathrm{S}}$ is the mass of the swollen material and $W_{\mathrm{d}}$ is the initial dry mass.

2.6. Protein Adsorption to SF/K Films. SF/K films were incubated with $0.1 \mathrm{U} / \mathrm{mL}$ of PPE solution at $37{ }^{\circ} \mathrm{C}$ for $24 \mathrm{~h}$. We determined adsorption of the proteins to the $\mathrm{SF} / \mathrm{K}$ films by measuring the reduction of elastase activity in the supernatant.

2.7. Atomic Force Microscopy (AFM). Surface analysis of the films was performed in tapping mode using a Nanoscope III scanning probe microscope controller (Multimode Digital Instruments) with a silicon probe (RTESP14, Veeco). Root mean square (rms) roughness data were collected from each sample according to manufacture instructions. Two scans of $10 \mu \mathrm{m} \times 10 \mu \mathrm{m}$ edge regions were taken for each dry sample.

2.8. Cytotoxicity Evaluation. SF/K films were tested for cytotoxicity according to the ISO standards (10993-5, 2009). Both, tests by direct contact and tests on extract were performed to analyze the cytotoxicity of the developed materials.

Cell Culture. The NIH 3 T3 cell line (mouse embryonic fibroblasts) was maintained in Dulbecco's modified Eagle's medium (DMEM) supplemented with $10 \%(\mathrm{v} / \mathrm{v})$ of fetal bovine serum (FBS) inactivated $\left(20 \mathrm{~min}\right.$ at $56^{\circ} \mathrm{C}$ ) and $1 \%(\mathrm{v} / \mathrm{v})$ of penicillin/streptomycin (PS; 10000 units $/ \mathrm{mL}$ penicillin and $10000 \mu \mathrm{g} / \mathrm{mL}$ streptomycin) all supplied by Gibco. The cells were maintained at $37{ }^{\circ} \mathrm{C}$ in a humidified atmosphere of $5 \% \mathrm{CO}_{2}$. The medium was refreshed every 2 to 3 days. At preconfluence, cells were harvested using trypsin $(0.25 \%(\mathrm{w} / \mathrm{v})$ trypsin, $0.1 \%(\mathrm{w} / \mathrm{v})$ glucose, and $0.05 \%(\mathrm{w} / \mathrm{v})$ ethylenediaminetetraacetic acid (EDTA) in phosphate-buffered saline solution (PBS)) and further used as described in the following paragraphs.
Test on Extracts. Discs $(\phi=8 \mathrm{~mm})$ were punched out of the films with skin biopsy punches (Acu-Punch) and sterilized by immersion in serial dilutions of ethanol $(90,70$, and $50 \% \mathrm{v} / \mathrm{v})$ for $15 \mathrm{~min}$, then hydrated and rinsed with PBS. The extracts were obtained by the incubation of the membranes in $2 \mathrm{~mL}$ of DMEM supplemented with $1 \%(\mathrm{v} / \mathrm{v}) \mathrm{PS}$ in an orbital incubator at $37{ }^{\circ} \mathrm{C}$ for either 24 and $72 \mathrm{~h}$ at $180 \mathrm{rpm}$. At the end of these time points, the membranes were removed, and the extracts were obtained. Before use, the extracts were supplemented with $10 \%(\mathrm{v} / \mathrm{v})$ FBS and subsequently serially diluted (100, $50,25$, and $10 \%(\mathrm{v} / \mathrm{v}))$ in complete culture medium. A sample of the extract vehicle subjected to the same extraction conditions was used as a negative control, whereas a $1 \%(\mathrm{v} / \mathrm{v})$ solution of Triton X-100 (Sigma) prepared in fresh culture medium was used as a positive control. Cells seeded at a density of $5 \times 10^{3}$ cells/200 $\mu \mathrm{L} /$ well on 96 -well tissue culture polystyrene (TCPS) plates (Greiner Bio-one) were exposed to the serial dilutions of the extracts and incubated at $37{ }^{\circ} \mathrm{C}$ under a humidified atmosphere of $5 \% \mathrm{CO}_{2}$. At the end of each culture period (24 and $72 \mathrm{~h}$ ), the cell viability was assessed using a resazurin based assay. Medium containing extract was refreshed ever $24 \mathrm{~h}$ of contact with the cells.

Test by Direct Contact. This test was performed to monitor the effect of the materials on fibroblast proliferation upon direct contact. Discs, prepared and sterilized as previously described $(\phi=14 \mathrm{~mm})$, were gently place in 24-well TCPS plates (Greiner Bio-one) and fixed with sterilized silicone rings with a $12 \mathrm{~mm}$ internal diameter (Epidor, Spain). The discs were let to dry overnight in a laminar flow hood. Prior to cell seeding, discs were equilibrated in PBS and subsequently in DMEM with $1 \% \mathrm{v} / \mathrm{v}$ PS $\left(37^{\circ} \mathrm{C}\right.$ for $1 \mathrm{~h}$ ). We seeded and cultured $2 \times 10^{4}$ cells $/ \mathrm{mL} /$ well for 24,48 , and $72 \mathrm{~h}$. TCPS in the presence of the o-rings was used as control. Medium was refreshed daily. After each incubation periods, cell proliferation was determined quantitatively using the resazurin based assay, and cell morphology was assessed using F-actin fluorescent labeling.

Resazurin Assay. Resazurin is a blue, nonfluorescent molecule that is reduced by several mitochondrial and cytoplasmic enzymes to a pink fluorescent product, called resofurin. $10 \%(\mathrm{v} / \mathrm{v})$ of resazurin solution $(0.1 \mathrm{mg} / \mathrm{mL}$, in PBS) was added to each well. After $4 \mathrm{~h}$ of incubation at $37{ }^{\circ} \mathrm{C}, 200 \mu \mathrm{L}$ of the medium was transferred into a black-walled 96-well plate (Greiner Bio-one), and fluorescence was measured at excitation and emission wavelengths of 530 and $590 \mathrm{~nm}$, respectively. (Spectra Max Gemini XS - molecular devices).

$F$-actin Fluorescence Labeling. After each incubation period, the samples were rinsed with PBS and fixed with $4 \%$ (w/v) $p$-formaldehyde in PBS for $10 \mathrm{~min}$. After washing with PBS, cells were permeabilized with $0.1 \%(\mathrm{v} / \mathrm{v})$ Triton X-100 (Sigma) in PBS for $10 \mathrm{~min}$ and then washed three times with PBS. We visualized cell cytoskeletal filamentous actin (F-actin) by treating the cells with $5 \mathrm{U} / \mathrm{mL}$ Alexa Fluor 488 phalloidin (Molecular Probes) for $20 \mathrm{~min}$ in the dark. Cells were then washed three times with PBS, and cell nuclei were counterstained with 4',6-diamidino-2-phenylindole (DAPI) dye. Cells were examined using an inverted fluorescence microscope (Axiovert 200M, Zeiss, Germany).

2.9. Mass Spectrometry. We performed mass spectrometry analysis to determine the hydrolysis rate of the peptide by elastase. Mass spectra were obtained using a LxQ MS detector, Thermo Electron Corporation. Samples were dissolved in methanol and ionized by electrospray ionization (ESI). The scan range was from $\mathrm{m} / \mathrm{z} 100$ to 2000 in positiveion mode.

2.10. In Vitro Release. The release of model compounds from $S F / K$ films was evaluated by the incorporation of FITC-BSA in the films. FITC-BSA ( $2 \mathrm{mg} / \mathrm{mL}$ ) was mixed with protein solutions before film casting. The resulting films incorporating FITC-BSA were incubated with $100 \mathrm{mM}$ Tris-HCl buffer, $\mathrm{pH} 8.0$, and $0.1 \mathrm{U} / \mathrm{mL}$ of PPE solution at $37^{\circ} \mathrm{C}$. Solutions were changed every day. At determined time points, aliquots were taken, and the FITC-BSA release was monitored by a multiplate reader (Synergy HT W/TRF from BioTek) in the fluorescence mode at emission wavelength of $490 \mathrm{~nm}$. After each measurement, the samples were added back to the medium to restore the equilibrium 
conditions. The quantification of the release was established by a standard fluorescence curve. The release studies were performed in triplicate and for a period of 7 days.

2.11. Release Kinetics. The release behavior of compounds from polymeric systems can be determined by fitting the release data to the empirical relationship given by the Ritger-Peppas equation. ${ }^{23}$

$$
\frac{M_{t}}{M_{\infty}}=k t^{n}
$$

Where $M_{t}$ is the amount of compound release at time $t ; M_{\infty}$ is the amount of compound at time approaching infinity; $t$ is the release time; $k$ is the kinetic constant, and $n$ is the diffusion exponent characteristic of the release mechanism.

To determine $n$ values for $\mathrm{SF} / \mathrm{K}$ films, eq 3 is modified in eq 4, and $n$ is determined from the slope of the plot of $\log$ (\% release) versus $\log t$.

$$
\log (\% \text { released })=\log \left(M_{t} / M_{\infty}\right)=\log k+n \log t
$$

2.12. Elastase Activity Determinations. The activity of PPE was measured according to a method previously reported ${ }^{24}$ with some modifications. In brief, $30 \mu \mathrm{L}$ of enzyme was mixed with $900 \mu \mathrm{L}$ of reaction buffer $100 \mathrm{mM}$ Tris- $\mathrm{HCl}, \mathrm{pH}$ 8.0. The reaction was started by the addition of $70 \mu \mathrm{L}$ of $4.4 \mathrm{mM}$ of Suc-Ala-Ala-Ala- $p$-nitroanilide, a synthetic substrate for PPE. The reaction was carried out for $5 \mathrm{~min}$ at $37^{\circ} \mathrm{C}$, and the cleavage of the substrate was monitored spectrophotometrically at $410 \mathrm{~nm}$. One unit is defined as the amount of enzyme that will hydrolyze $1.0 \mu \mathrm{mol}$ of Suc-(Ala) $)_{3}-p$ NA per minute at $25^{\circ} \mathrm{C}$, $\mathrm{pH} 8.0$.

To examine the inhibitory activity of 5(6)-carboxyfluoresceinYCQPPWSATCF-OH, different peptide concentrations were added to a fixed amount of PPE solution. The incubation was carried out a 37 ${ }^{\circ} \mathrm{C}$, and at determined time points, aliquots were taken to monitor the decrease in elastase activity determined as previously described.

To evaluate if the developed materials present inhibitory properties, $20 \mu \mathrm{M}$ of peptide was mixed with the proteins solutions before film casting. The films were incubated with PPE solution at $37{ }^{\circ} \mathrm{C}$. In this case, a fixed ratio of elastase solution per weight of film $(0.2 \mathrm{~mL} / \mathrm{mg}$ film) was kept. The inhibitory activity was determined as described above.

2.13. Statistical Analyses. Data are presented as average \pm standard deviation (SD). For multiple comparisons, homogeneity of variances was assessed by Barlett's test and after confirmation of the nonsignificant difference of variances, one-way ANOVA, followed by post hoc Bonferroni test. Differences were considered statistically significant when $p<0.05$. All calculations were performed using SPSS software for Windows (version 16.0, SPSS).

\section{Results and Discussion}

In this work, films designed to be wound-dressing materials, based on SF and keratin proteins with delivery properties, were developed.

Our previous work ${ }^{22}$ indicated that SF and keratin are able to establish intermolecular interactions like hydrogen bonding. This fact was proven by the nonlinear trend of the different parameters such as intensity ratio of amide II bands and enthalpy variation $(\Delta H)$ of the decomposition peak obtained, respectively, from FTIR and DSC analysis. In addition, in the presence of protease enzyme, the films underwent a slow biological degradation, which is a function of the amount of keratin present in the blend.

The combination of our results with the excellent biocompatibility both in vitro and in vivo, ${ }^{25,26}$ the promotion of cellular

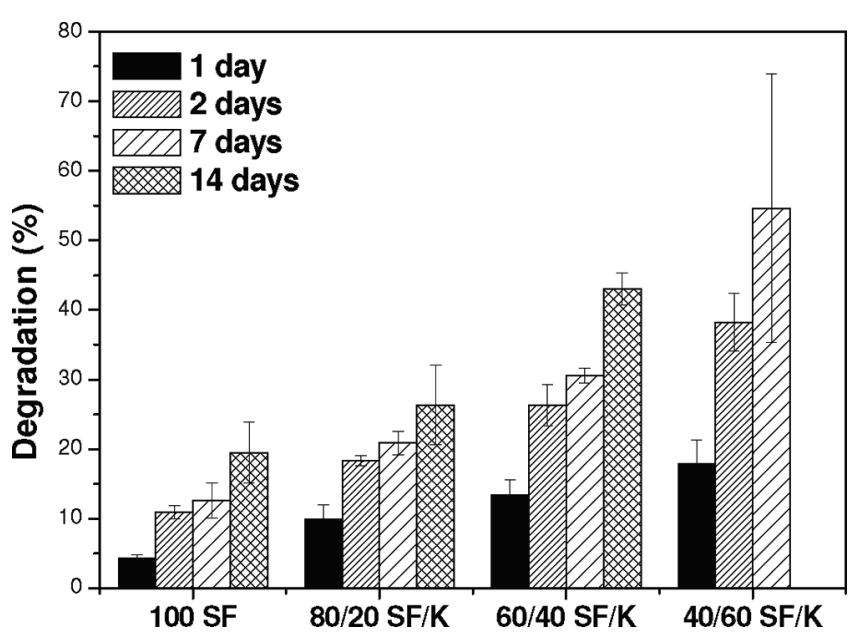

Figure 1. In vitro degradation of protein films incubated with $0.1 \mathrm{U} / \mathrm{mL}$ of elastase solution at $37^{\circ} \mathrm{C}$ for several days.

adhesion and proliferation, ${ }^{27-29}$ and slow biodegradation already demonstrated were the main factors to study the ability of SF/K films to act as wound dressings.

3.1. Characterization of Protein Blend Films. Films were prepared by casting the regenerated solutions of SF and keratin on Petri dishes. After overnight solvent evaporation, uniform and transparent films were obtained. Blend films with concentrations of: $100,80,60,40,20$, and $0 \%$ of SF were prepared. However, it was observed that with the increase in keratin in the blend it was not possible to obtain a film with mechanical integrity. Therefore, the maximum concentration of keratin that can be used in the blend is $60 \%$.

Degradability of a given material is a very important parameter. It is directly linked to the drug release. The fast polymer degradation is not desirable because a high drug concentration will be released, which can be disadvantageous.

In vitro degradation of $\mathrm{SF} / \mathrm{K}$ films was determined by incubating protein films for several days in the presence of elastase enzyme, which is one of the major components of the chronic wounds exudate. PPE was used as a model.

It can be observed (Figure 1) that pure SF films present a low degradation rate that remains constant over the time exposure to elastase. This weight loss can be related with the degradation of the small hydrolytically peptide sequences present on the films even after crystallization. ${ }^{30}$

In the blends, it can be observed that the weight loss obtained is a function of keratin content present in the film. At low keratin amounts $(20 \%)$, the degradation is relatively slower. At maximum keratin concentration $(60 \%)$, the degradation took place rapidly, and after 7 days, we obtained debris. Consequently, the weight loss for this sample after 14 days of incubation was not measured because of the high error associated with the measurement.

It is important to notice that the weight loss obtained for the blends is almost the same as the keratin content on the blend. Therefore, the debris obtained for $40 / 60 \mathrm{SF} / \mathrm{K}$ film is probably the fibroin that is not degraded but is not in sufficient amount to maintain the mechanical structure of the film. From our results, the maximum keratin amount that promotes a constant degradation is $40 \%$. The films kept in buffer solution showed little or no degradation in 14 days.

On the wound dressing research, swelling is other important parameter in materials characterization. If the material has the ability to swell, then it will give moisture to the wound, contributing to better healing. ${ }^{12}$ The swelling ratio was found 


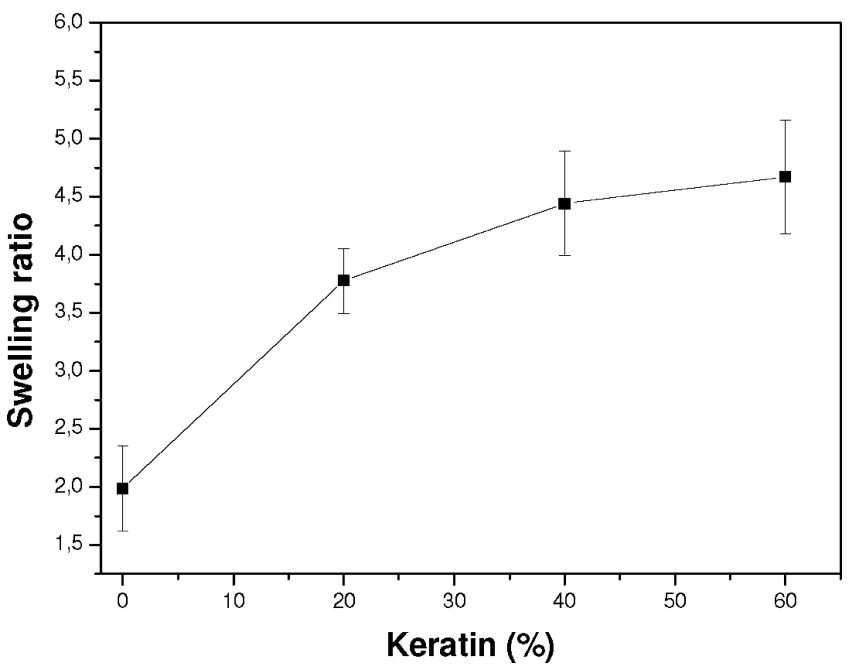

Figure 2. Swelling ratio calculated after $24 \mathrm{~h}$ of incubation in 100 $\mathrm{mM}$ Tris- $\mathrm{HCl}$ buffer, $\mathrm{pH} 8.0$ at $37^{\circ} \mathrm{C}$.

to increase with the increase in keratin present in the blend (Figure 2). Swelling results from diffusion and involves the transport of ions or fluid into the biomaterial. The driving forces of film formation by casting and solvent evaporation are attributed to hydrophobic interactions and partial electrostatic interactions. ${ }^{30}$ The increase in keratin amount decreases these types of interactions because of the high content in polar residues such as cysteine. This will promote a more open structure, thereby increasing the film swelling.

SF/keratin films morphology was assessed by AFM. With this analysis, we intend to determine the effect of surface topography on the degradation as well on cell adhesion. In Figure 3, the roughness height images are shown. The pure SF film presented the higher roughness value, and its surface is characterized by well-defined globular structures (Figure 3a), as already observed by other authors. ${ }^{31}$ The formation of these structures is a consequence of the methanol treatment.

In the blends, the addition of keratin enables the formation of the globular structures, making the surface of the film smoother. A decrease in the roughness value with the increase in keratin in the blend can also be observed. (Data not shown.)

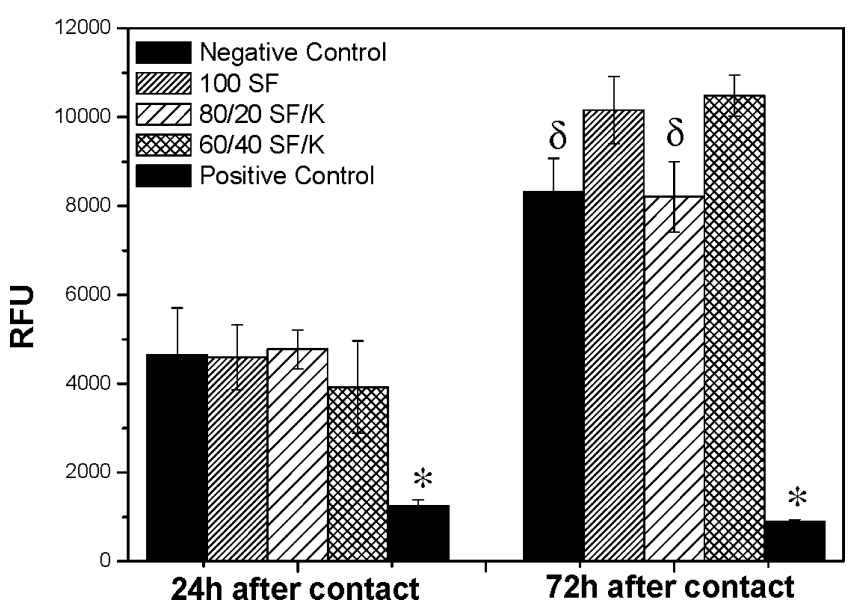

Figure 4. NIH 3 T3 cell viability at 24 and $72 \mathrm{~h}$ of culture post contact with extracts of the different materials tested (72 h extraction time). The relative fluorescence units (RFUs) are presented for each material and for each time point. The data represent a mean \pm SD of six independent measurements. The results obtained with the four materials were compared among each other and with the controls: * $=$ significantly different from all of the other tested conditions; $\delta=$ significantly different from $100 \mathrm{SF}, 80 / 20 \mathrm{SF} / \mathrm{K}$, and 60/40 SF/K.

The addition of keratin alters the surface topography of the films, and as a consequence, this might cause loss of film strength, as already confirmed by in vitro degradation results. ${ }^{32}$

Biocompatibility is an essential parameter to be evaluated for a biomaterial to be used in wound dressing. This was assessed for our materials through the use of mouse embryonic fibroblasts cultures. Two parameters were determined, cytotoxicity and cell adhesion. The results of the indirect contact study following fibroblast incubation with material extracts at different dilutions showed no cytotoxicity effect of the protein film extracts regardless of the extraction time. Figure 4 represents the viability results for cells in contact with undiluted extract (extraction time $72 \mathrm{~h}$ ). In all cases, the metabolic activity of cells in contact with the extracts was statistically equal or higher than the one obtained with negative control (complete medium).

Direct contact study performed by seeding the cells on the membranes showed a time-dependent increase in cell metabolic
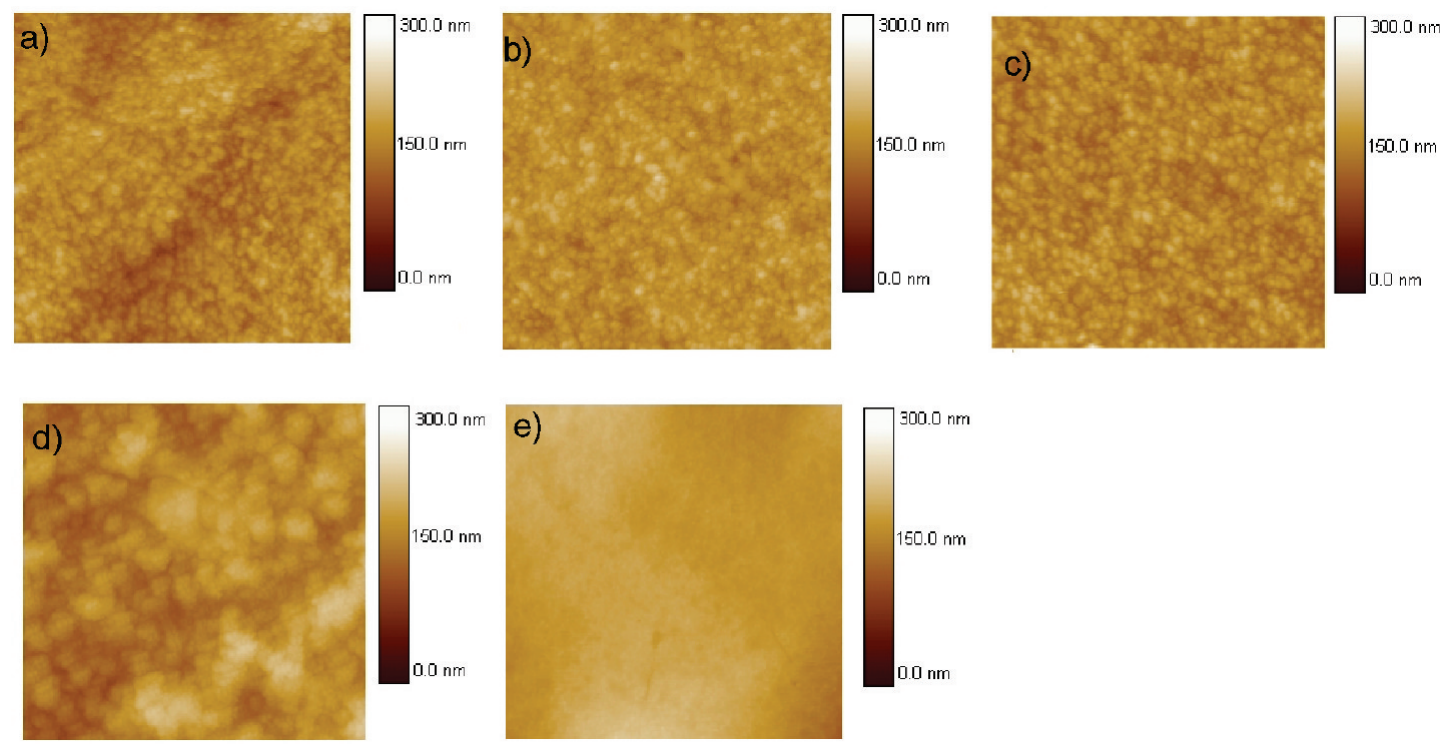

Figure 3. AFM height images of pure and blend silk fibroin/keratin films. (a) $100 \mathrm{SF}$, (b) $80 \mathrm{SF}$, (c) $60 \mathrm{SF}$, (d) $40 \mathrm{SF}$, (e) $100 \mathrm{~K}$. The area measured was $10 \times 10 \mu \mathrm{m}$. 


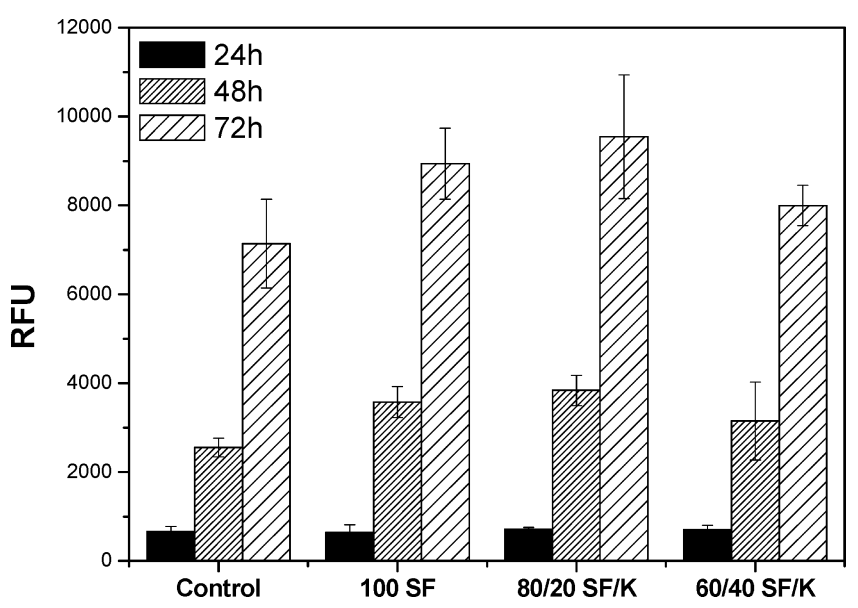

Figure 5. NIH 3T3 cell proliferation on discs of $100 \mathrm{SF}, 80 / 20 \mathrm{SF} / \mathrm{K}$, and $60 / 40 \mathrm{SF} / \mathrm{K}$. The relative fluorescence units (RFUs) are presented for each material and for each time point. The data represent a mean \pm SD of three independent measurements.

activity (Figure 5) that may suggest an increase in cell proliferation. This was confirmed by cell microscopic observation where cell number increased as a function of time. However, at the different time points studied, no significant differences were observed among the materials and the control, suggesting that the structures observed in AFM analysis on the film surface did not affect cellular adhesion. Microscopic observations showed similar cell number, distribution, and morphology on all materials, regardless of the time of contact. At $48 \mathrm{~h}$ (Figure 6 ), cells exhibited an elongated morphology with fusiform fibroblastic appearance already at confluence, as on the control (TCPS). F-actin staining revealed a well-defined cytoskeleton and numerous filopodia as well as cell-cell contacts. The same result was observed by Shudong et al. using mouse fibroblast cell lines. ${ }^{33}$ These results are in agreement with the literature, indicating that the processing steps involving the use of solvent systems will not cause detrimental effects on the resulting material. ${ }^{34-37}$
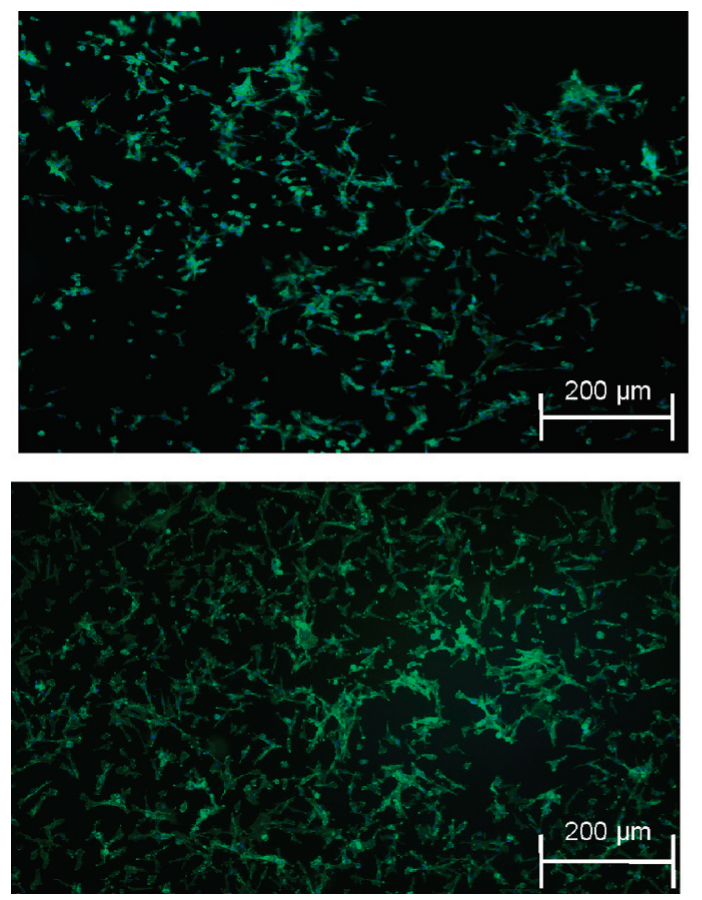

Figure 6. Fluorescent labeling of F-actin (green) and DNA (blue) of NIH 3 T3 cells cultured for $48 \mathrm{~h}$ on TCPS (A and B) and discs prepared from 80/20 SF/K film (C and D).
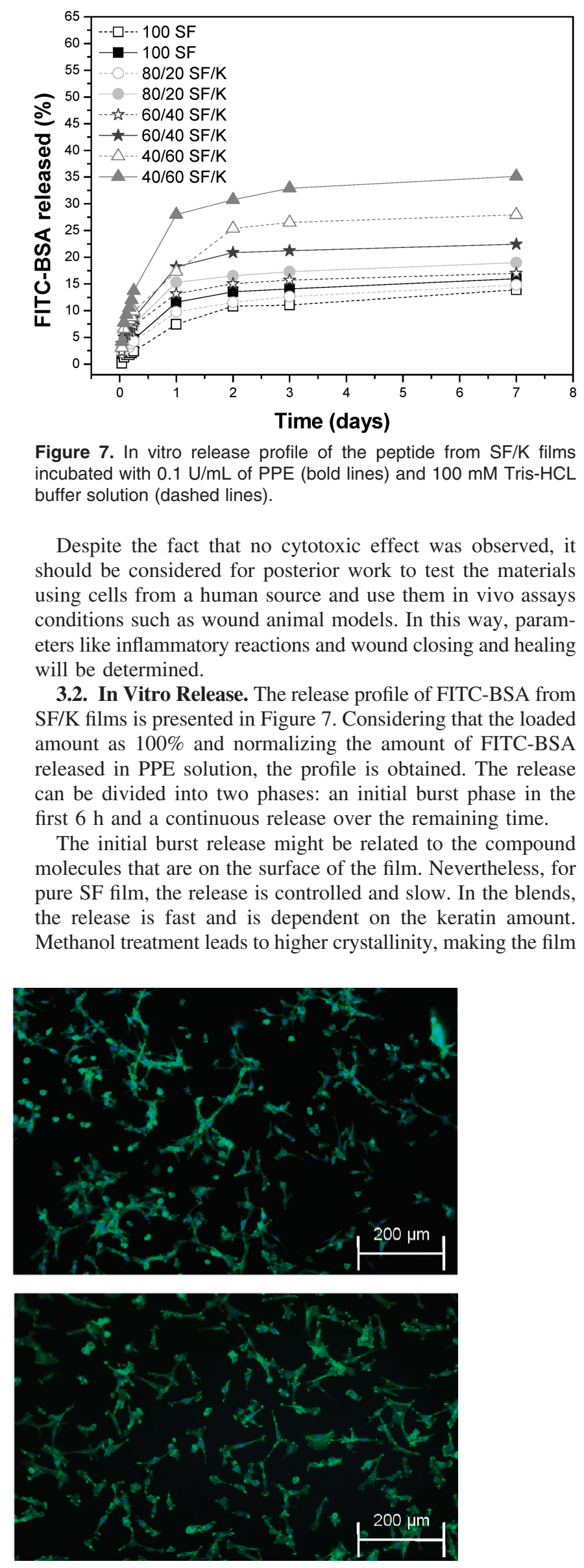

Figure 7. In vitro release profile of the peptide from SF/K films incubated with $0.1 \mathrm{U} / \mathrm{mL}$ of PPE (bold lines) and $100 \mathrm{mM}$ Tris-HCL buffer solution (dashed lines).

Despite the fact that no cytotoxic effect was observed, it should be considered for posterior work to test the materials using cells from a human source and use them in vivo assays conditions such as wound animal models. In this way, parameters like inflammatory reactions and wound closing and healing will be determined.

3.2. In Vitro Release. The release profile of FITC-BSA from $\mathrm{SF} / \mathrm{K}$ films is presented in Figure 7. Considering that the loaded amount as $100 \%$ and normalizing the amount of FITC-BSA released in PPE solution, the profile is obtained. The release can be divided into two phases: an initial burst phase in the first $6 \mathrm{~h}$ and a continuous release over the remaining time.

The initial burst release might be related to the compound molecules that are on the surface of the film. Nevertheless, for pure SF film, the release is controlled and slow. In the blends, the release is fast and is dependent on the keratin amount. Methanol treatment leads to higher crystallinity, making the film 
Table 1. Model Compound Release Kinetic Data Obtained from Fitting Experimental Release Data to Ritger-Peppas Equation where " $n$ " Is the Diffusion Exponent and $R^{2}$ Is the Correlation Coefficient

\begin{tabular}{lll}
\hline sample & $n$ & $R^{2}$ \\
\hline $100 \mathrm{SF}$ & 0.411 & 0.996 \\
$80 / 20 \mathrm{SF} / \mathrm{K}$ & 0.507 & 0.997 \\
$60 / 40 \mathrm{SF} / \mathrm{K}$ & 0.551 & 0.997 \\
$40 / 60 \mathrm{SF} / \mathrm{K}$ & 1.03 & 0.993 \\
\hline
\end{tabular}

rigid and compact. Although this treatment leads to physical cross-linking of the films, incorporation of keratin, of hydrolytic nature, had a pronounced effect on the FITC-BSA release. This may be due to keratin dissolution causing more void volume for the release of the compound. The methanol treatment does not provide adequate stability for sustained release over days for films with high keratin content.

The previous results obtained from mechanical tests ${ }^{22}$ indicate that increase in keratin content leads to the decrease in the mechanical strength of the films. This will allow the formation of cracks in the film from where the compound can rapidly diffuse out.

To evaluate if the release from $\mathrm{SF} / \mathrm{K}$ films is controlled by diffusion or dominated by film degradation, we fit experimental data into the Ritger-Peppas equation, as described in Section 2.11 .

For a thin film, a Fickian diffusion of first-order is observed when $n$ has the limiting value of 0.5 ; when $n=1$, case II transport (polymer relaxation/degradation) occurs, leading to zero-order release. When $n$ lies between 0.5 and 1 , anomalous transport is observed, coupling Fickian diffusion and polymer degradation. ${ }^{38}$

It can be concluded from the data obtained in Table 1 that samples $100 \mathrm{SF}$ and $80 / 20 \mathrm{SF} / \mathrm{K}$ indicate that the release is dominated by Fickian diffusion of first-order. The $n$ value obtained for the blend $80 / 20 \mathrm{SF} / \mathrm{K}$ is closer to 0.5 , indicating that the addition of $20 \%$ of keratin decreases the rigidity of the compact structure of pure SF film, improving the release properties. There is an increase in film swelling and consequently the diffusion of FITC-BSA.

For the blend $60 / 40 \mathrm{SF} / \mathrm{K}$, the release is non-Fickian nature. " $n$ " lies between 0.5 and 1 , indicating that the release is due to the combination of diffusion and film degradation.

The sample 40/60 SF/K shows the highest " $n$ " value $(n>1)$, indicating that for this sample the release is totally dominated by film degradation. The sample $40 / 60 \mathrm{SF} / \mathrm{K}$ presents higher swelling ratio and degradation rate and, as a consequence, higher release rate. Furthermore, correlation coefficient " $R$ " is above the permissible range, that is, $R^{2}=0.95$, indicating the validity of the results.

3.2. Inhibitory Activity. The major goal of this work is the development of wound dressings with specific biological functionality: the inhibition of high levels of elastase. For this purpose, it was important to determine the inhibitory activity of the synthetic peptide selected.

Several studies have been made to control elastase activity and promote chronic wound healing. A cotton-bound serine protease inhibitor has shown to decrease elastase activity on a chronic wound fluid. ${ }^{39}$ The release of epidermal growth factor (EGF) from electrospun silk mats had also shown the promotion of wound healing. ${ }^{40}$ Even so, there are few or no studies on the release of synthetic peptides from protein films to promote the inhibition of high levels of elastase found on chronic wounds
Table 2. Half-Life Time of PPE Activity after $24 \mathrm{~h}$ of Incubation with Different Peptide (5(6)-Carboxyfluorescein-YCQPPWSATCF$\mathrm{OH})$ Concentrations at Room Temperature

\begin{tabular}{lr}
\hline sample & \multicolumn{1}{c}{$t_{1 / 2}(\mathrm{~h})$} \\
\hline $\mathrm{PPE}$ & $28.3 \pm 3.7$ \\
$\mathrm{PPE}+20 \mu \mathrm{M}$ & $15.3 \pm 2.1$ \\
$\mathrm{PPE}+40 \mu \mathrm{M}$ & $11.6 \pm 2.3$ \\
$\mathrm{PPE}+60 \mu \mathrm{M}$ & $5.3 \pm 1.2$ \\
$\mathrm{PPE}+80 \mu \mathrm{M}$ & $3.8 \pm 1.1$ \\
\hline
\end{tabular}

Table 3. Half-Life Time of PPE after $24 \mathrm{~h}$ of Incubation with SF/K Films with $20 \mu \mathrm{M}$ of Peptide Incorporated

\begin{tabular}{lc}
\hline sample & activity loss (\%) \\
\hline $\mathrm{PPE}$ & $28.3 \pm 3.7$ \\
$\mathrm{PPE}+20 \mu \mathrm{M}$ & $15.3 \pm 2.1$ \\
$100 \mathrm{SF}$ & $22.7 \pm 4.2$ \\
$80 / 20 \mathrm{SF} / \mathrm{K}$ & $17.5 \pm 3.3$ \\
$60 / 40 \mathrm{SF} / \mathrm{K}$ & $14.1 \pm 2.1$ \\
$40 / 60 \mathrm{SF} / \mathrm{K}$ & $8.1 \pm 1.1$ \\
\hline
\end{tabular}

exudate. Therefore, this work presents an original system to control high levels of elastase found on chronic wounds.

To determine the inhibitory activity of the peptide, increasing peptide amounts were incubated with elastase solution at 37 ${ }^{\circ} \mathrm{C}$. At determined time points, aliquots were taken to determine the residual activity. From the results obtained on Table 2, it can be seen that for high peptide concentrations PPE activity rapidly decreases, suggesting its ability to act as an elastase inhibitor. For lower peptide concentrations, the decrease in halflife time of PPE is not so pronounced. It can be concluded that the decrease in PPE activity is dependent on peptide concentration.

To understand the inhibition mechanism of this peptide, assays were performed to determine the inhibition constant. When the residual activity was plotted against substrate concentration, it was observed that the elastase activity curve in the presence of peptide inhibitor converge, over the time, to the curve of elastase activity without peptide. This result might indicate that the peptide is being hydrolyzed by elastase, which was confirmed by mass spectrometry analysis. (Data not shown.)

Hydrolytic stability of BBI peptides as the one selected for this study is very important. In general, hydrolysis rates are low and are affected by the peptide sequence..$^{21,41,42}$ The hydrolysis of our peptide occurred after $6 \mathrm{~h}$ of incubation with PPE. Nevertheless, a high decrease in elastase activity was observed in the presence of peptide (Table 2), suggesting that its function was not affected by hydrolysis. Simulations performed based on the decrease in the mass value (from $\mathrm{m} / \mathrm{z}=1659.83$ to $\mathrm{m} / \mathrm{z}$. $=1512.75$ ) indicated that hydrolysis might occur in one amino acid residue of the $\mathrm{C}$-terminal. This probably will not change the conformational structure of the peptide, which allows it to retain the inhibitory activity. However, this fact has to be further investigated by other techniques such as NMR analysis.

To determine if the peptide retains its inhibitory activity after incorporation onto SF/K films, films with $20 \mu \mathrm{M}$ of peptide were incubated with PPE solution for $24 \mathrm{~h}$. At determined time points, the PPE activity was measured, and the results are presented in Table 3 as half-life time of PPE. It can be seen that for $100 \mathrm{SF}$ and $80 / 20 \mathrm{SF} / \mathrm{K}$ films, incorporation of the peptide increases the half-life time of PPE $(22.7 \pm 4.2$ and 17.5 $\pm 3.3 \mathrm{~h}$, respectively) when compared with the peptide alone $(15.3 \pm 2.1 \mathrm{~h})$.

This result indicates the ability of the $\mathrm{SF} / \mathrm{K}$ films to act as elastase inhibitors wound dressings. For the blends 60/40 and $40 / 60 \mathrm{SF} / \mathrm{K}$, the half-life time of PPE decreases in comparison with the peptide in solution (Table 3 ). The release of the peptide 


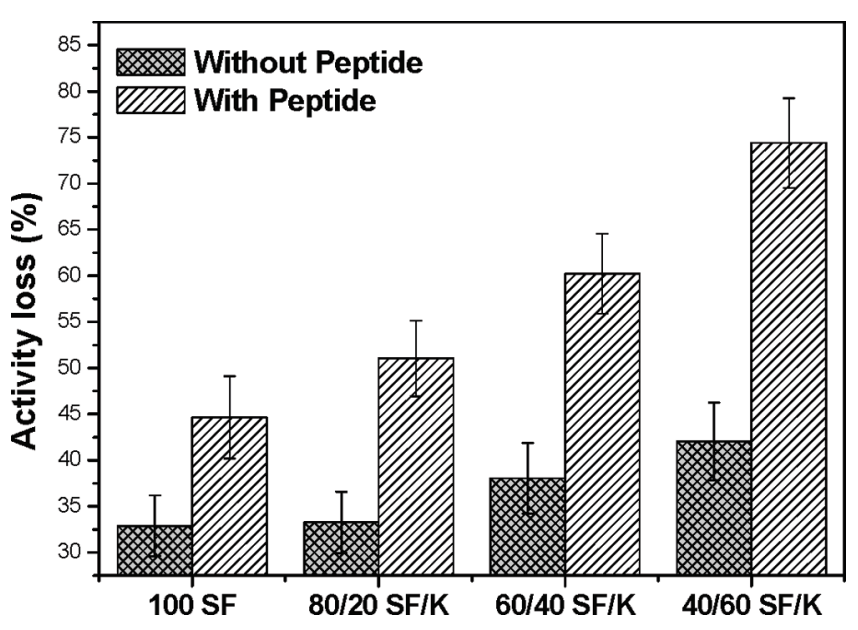

Figure 8. PPE activity loss after $24 \mathrm{~h}$ of incubation with SF/K films with and without peptide incorporated.

from $\mathrm{SF} / \mathrm{K}$ films was also monitored for $24 \mathrm{~h}$ by fluorescence measurements. (Data not shown.) With the data obtained, it was not possible to determine the release mechanism. Nevertheless, the release kinetics obtained with FITC-BSA allow us to conclude that in the first $24 \mathrm{~h}$ the decrease in PPE activity is mainly due to the swelling ratio.

The high swelling ratio obtained for $60 / 40$ and 40/60 SF/K blends means that PPE solution is rapidly in contact with inhibitor peptide into the film, causing the fast decrease in PPE activity. If the measurements were prolonged for more time, then the release of peptide and consequently the decrease in PPE activity will be more influenced by degradation rate.

In a heterogeneous system like this, it is important to determine the protein, PPE, adsorption to the SF/K films. In particular, it is important to distinguish the decrease in PPE activity due to the peptide action from the decrease in activity due to adsorption to the films.

To evaluate this difference, films with and without peptide were incubated with PPE solution, and the decrease in PPE activity was monitored. It can be seen from Figure 8 that when PPE was incubated with $\mathrm{SF} / \mathrm{K}$ films without peptide, the decrease in activity is much lower in comparison with films with peptide. This result validates the action of the peptide when it is incorporated into the SF/K films. Furthermore, it can be seen that protein (PPE) adsorption is also a function of the keratin amount.

\section{Conclusions}

This study evidenced that blending SF and wool keratin results in a protein matrix suitable for sustained delivery of elastase inhibiting agents. The release pattern is affected by the degradation rate of the films, and the knowledge of this allows the design of matrices with controlled release ability.

In vitro degradation was evaluated under PPE solution, and it was found that biological degradation is a function of keratin amount present in the film. The SF/K films were also tested for in vitro release using PPE solution as release medium. The results presented indicated that the release mechanism of molecules from the films is dominated by film degradation and diffusion. In this work, the dehydrating step of methanol treatment was used to control the structure and stability of the self-assembly SF/K films. Pure fibroin films (100 SF) present a rigid and compact structure; the addition of keratin leads to a decrease in $\beta$-sheet content, causing a more open structure that will affect swelling, degradation, and release rates. Furthermore, our study indicated that the protein films developed are not cytotoxic and are able to support the adhesion of fibroblasts cells, making them suitable for biomedical applications such as wound dressings.

Acknowledgment. We would like to acknowledge FCT Portuguese Foundation for Science and Technology for the scholarship concession; European project Lidwine, contract no. NMP2-CT-2006-026741, and Silvia Cappellozza from "Sezione Specializzata per la Bachicoltura" for the supply of silk cocoons.

\section{References and Notes}

(1) Boateng, J. S.; Matthews, K. H.; Stevens, H. N. E.; Eccleston, G. M. Wound healing dressings and drug delivery systems: a review. J. Pharm. Sci. 2008, 97, 2892-2923.

(2) Rothe, M.; Falanga, V. Growth factors: their biology and promise in dermatologic diseases and tissue repair. AMA Arch. Dermatol. 1989, 125, 1390-1398.

(3) Shakespeare, P. Burn wound healing and skin substitutes. Burns 2001, 27, 517-522.

(4) Martin, C. R. Wound infection: a failure of wound healing caused by an imbalance of bacteria. Surg. Clin. North Am. 1997, 77, 637-650.

(5) Stadelmann, W. K.; Digenis, A. G.; Tobin, G. R. Physiology and healing dynamics of chronic cutaneous wounds. Am. J. Surg. 1998, $176,26 \mathrm{~S}-38 \mathrm{~S}$

(6) Eaglstein WH, F. V. Chronic wounds. Surg. Clin. North Am. 1997, $77,689-700$

(7) Gray, D, W. R. The wound exudate continuum: an aid to wound assessment. Wounds U.K.: Appl. Wound Manageme. Suppl. 2004, 1921.

(8) Chen, W. Y. J.; Rogers, A. A.; Lydon, M. J. Characterization of biologic properties of wound fluid collected during early stages of wound healing. J. Invest. Dermatol. 1992, 99, 559-564.

(9) Brooke, B.; Edward, J. C.; Caroline, A. O. Leukocyte proteinases in wound healing: roles in physiologic and pathologic processes. Wound Repair Regener. 1999, 7, 410-422.

(10) Dorne, R. Y.; Benedict, C. N. The proteolytic environment of chronic wounds. Wound Repair Regener. 1999, 7, 433-441.

(11) Naomi, J. T.; Michael, C. S.; Shawn, M.; Neil, B.; Jane, G.; Frank, B.; Gillian, M.; Gregory, S. Analysis of the acute and chronic wound environments: the role of proteases and their inhibitors. Wound Repair Regener. 1999, 7, 442-452.

(12) Enoch, S.; Leaper, D. J. Basic science of wound healing. Surgery (Oxford) 2008, 26, 31-37.

(13) Chufa, H.; Margaret, A. H.; George, W. C.; Frank, A. Effects of chronic wound fluid on the bioactivity of platelet-derived growth factor in serum-free medium and its direct effect on fibroblast growth. Wound Repair Regener. 1999, 7, 97-105.

(14) Chen, P.; Rose, J.; Love, R.; Wei, C. H.; Wang, B. C. Reactive sites of an anticarcinogenic Bowman-Birk proteinase inhibitor are similar to other trypsin inhibitors. J. Biol. Chem. 1992, 267, 1990-1994.

(15) Werner, M. H.; Wemmer, D. E. Three-dimensional structure of soybean trypsin/chymotrypsin Bowman-Birk inhibitor in solution. Biochemistry 1992, 31, 999-1010.

(16) Guangda, L. I. N.; Wolfram, B.; Robert, H.; Chengwu, C. H. I.; Richard, A. E. The 0.25-nm X-ray structure of the Bowman-Birktype inhibitor from mung bean in ternary complex with porcine trypsin. Eur. J. Biochem. 1993, 212, 549-555.

(17) Voss, R.-H.; Ulrich, E.; Lars-Oliver, E.; Gabriele, W.; Young-Mi, K.; Peter, F. Crystal structure of the bifunctional soybean Bowman-Birk inhibitor at 0.28-nm resolution. Eur. J. Biochem. 1996, 242, 122131.

(18) Wolfram, B.; Robert, H. Natural protein proteinase inhibitors and their interaction with proteinases. Eur. J. Biochem. 1992, 204, 433-451.

(19) Laskowski, M.; Qasim, M. A. What can the structures of enzymeinhibitor complexes tell us about the structures of enzyme substrate complexes. Biochim. Biophys. Acta, Protein Struct. Mol. Enzymol. 2000, 1477, 324-337.

(20) McBride, J. D.; Leatherbarrow, R. J. Synthetic peptide mimics of the Bowman-Birk inhibitor protein. Curr. Med. Chem. 2001, 8, 909917.

(21) Jeffrey, D. M.; Emma, M. W.; Arnd, B. E. B.; Agnès, M. J.; Robin, J. L. Peptide mimics of the Bowman-Birk inhibitor reactive site loop. Pept. Sci. 2002, 66, 79-92. 
(22) Vasconcelos, A.; Freddi, G.; Cavaco-Paulo, A. Biodegradable materials based on silk fibroin and keratin. Biomacromolecules 2008, 9, 12991305.

(23) Ritger, P. L.; Peppas, N. A. A simple equation for description of solute release II. Fickian and anomalous release from swellable devices. $J$. Controlled Release 1987, 5, 37-42.

(24) Tanaka, H.; Shimazu, T.; Sugimoto, H.; Yoshioka, T.; Sugimoto, T. A sensitive and specific assay for granulocyte elastase in inflammatory tissue fluid using L-pyroglutamyl-L-prolyl-L-valine- $p$-nitroanilide. Clin. Chim. Acta 1990, 187, 173-180.

(25) Yamauchi, K.; Maniwa, M.; Mori, T. Cultivation of fibroblast cells on keratin-coated substrata. J. Biomater. Sci., Polym. Ed. 1998, 9, 259 270.

(26) Li, M.; Ogiso, M.; Minoura, N. Enzymatic degradation behavior of porous silk fibroin sheets. Biomaterials 2003, 24, 357-365.

(27) Minoura, N.; Aiba, S.; Higuchi, M.; Gotoh, Y.; Tsukada, M.; Imai, Y. Biochem. Biophys. Res. Commun. 1995, 208, 511.

(28) Yamauchi, K.; Hojo, H.; Yamamoto, Y.; Tanabe, T. Enhanced cell adhesion on RGDS-carrying keratin film. Mater. Sci. Eng., C 2003, 23, 467-472.

(29) Roh, D.-H.; Kang, S.-Y.; Kim, J.-Y.; Kwon, Y.-B.; Young Kweon, H.; Lee, K.-G.; Park, Y.-H.; Baek, R.-M.; Heo, C.-Y.; Choe, J.; Lee, J.-H. Wound healing effect of silk fibroin/alginate-blended sponge in full thickness skin defect of rat. J. Mater. Sci.: Mater. Med. 2006, 17, 547-552.

(30) Lu, S.; Wang, X.; Lu, Q.; Hu, X.; Uppal, N.; Omenetto, F. G.; Kaplan, D. L. Stabilization of Enzymes in Silk Films. Biomacromolecules 2009, 10, 1032-1042.

(31) Hofmann, S.; Wong Po Foo, C. T.; Rossetti, F.; Textor, M.; VunjakNovakovic, G.; Kaplan, D. L.; Merkle, H. P.; Meinel, L. Silk fibroin as an organic polymer for controlled drug delivery. J. Controlled Release 2006, 111, 219-227.

(32) Numata, K.; Cebe, P.; Kaplan, D. L. Mechanism of enzymatic degradation of beta-sheet crystals. Biomaterials 2010, 31, 2926-2933.

(33) Shudong, W.; Youzhu, Z.; Guibo, Y.; Hongwei, W.; Zhihui, D. Electrospun polylactide/silk fibroin-gelatin composite tubular scaffolds for small-diameter tissue engineering blood vessels. J. Appl. Polym. Sci. 2009, 113, 2675-2682.
(34) Motta, A.; Migliaresi, C.; Faccioni, F.; Torricelli, P.; Fini, M.; Giardino, R. Fibroin hydrogels for biomedical applications: preparation, characterization and in vitro cell culture studies. J. Biomater. Sci., Polym. Ed. 2004, 15, 851.

(35) Bondar, B.; Fuchs, S.; Motta, A.; Migliaresi, C.; Kirkpatrick, C. J. Functionality of endothelial cells on silk fibroin nets: comparative study of micro- and nanometric fibre size. Biomaterials 2008, 29, 561-572.

(36) Fuchs, S.; Motta, A.; Migliaresi, C.; Kirkpatrick, C. J. Outgrowth endothelial cells isolated and expanded from human peripheral blood progenitor cells as a potential source of autologous cells for endothelialization of silk fibroin biomaterials. Biomaterials 2006, 27, 5399_ 5408.

(37) Unger, R. E.; Wolf, M.; Peters, K.; Motta, A.; Migliaresi, C.; James Kirkpatrick, C. Growth of human cells on a non-woven silk fibroin net: a potential for use in tissue engineering. Biomaterials 2004, 25, 1069-1075.

(38) Huang, Y.; Yu, H.; Xiao, C. pH-sensitive cationic guar gum/ poly(acrylic acid) polyelectrolyte hydrogels: swelling and in vitro drug release. Carbohydr. Polym. 2007, 69, 774-783.

(39) Edwards, J. V.; Alvin, F. B.; Sarah, B.; Abul, J. U.; I. Kelman, C.; Robert, F. D.; Steven, J. M. Inhibition of elastase by a synthetic cottonbound serine protease inhibitor: in vitro kinetics and inhibitor release. Wound Repair Regener. 1999, 7, 106-118.

(40) Schneider, A.; Wang, X. Y.; Kaplan, D. L.; Garlick, J. A.; Egles, C. Biofunctionalized electrospun silk mats as a topical bioactive dressing for accelerated wound healing. Acta Biomater. 2009, 5, 2570-2578.

(41) Gariani, T.; McBride, J. D.; Leatherbarrow, R. J. The role of the P2' position of Bowman-Birk proteinase inhibitor in the inhibition of trypsin: Studies on $\mathrm{P} 2$ ' variation in cyclic peptides encompassing the reactive site loop. Biochim. Biophys. Acta, Protein Struct. Mol. Enzymol. 1999, 1431, 232-237.

(42) Zablotna, E.; Kazmierczak, K.; Jaskiewicz, A.; Stawikowski, M.; Kupryszewski, G.; Rolka, K. Chemical synthesis and kinetic study of the smallest naturally occurring trypsin inhibitor SFTI-1 isolated from sunflower seeds and its analogues. Biochem. Biophys. Res. Commun. 2002, 292, 855-859.

BM100537B 